\title{
A HISTÓRIA AMBIENTAL E EDUCAÇÃO AMBIENTAL: REFLEXÕES EM 'ZONAS DE SACRIFÍCIO' NA BAIXADA FLUMINENSE/RJ
}

\author{
ENVIRONMENTAL HISTORY AND ENVIRONMENTAL EDUCATION: REFLECTIONS ON \\ 'AREAS OF SACRIFICE' IN BAIXADA FLUMINENSE/RJ
}

\author{
Edileuza Queiroz \\ Patricia Plácido
}

\section{Resumo}

Este trabalho tem a pretensão de contribuir com reflexões acerca da História Ambiental da Baixada Fluminense, região complexa nas diversas dimensões. A relevância deste estudo apresenta-se à medida que busca através da História Ambiental identificar e compreender as particularidades e as recorrências de fatores que possibilitaram a expansão significativa das atuais indústrias localizadas no território da Baixada Fluminense. A socialização, localização e distribuição espacial dos custos ambientais advindos das atividades industriais são estrategicamente definidos pela economia mundial. Esses espaços são definidos como 'zonas de sacrifício' (Acselrad 2005). Para o desenvolvimento deste estudo nos orientamos pelo enquadramento teórico-conceitual da ecologia política (Acserlrad 2004; Martinez-Alier 1999; Carneiro 2005; Kurz 1996; Lipietz 2002; Lima 2009) que tem como eixo a reflexão crítica sobre os nexos entre as práticas sociais de apropriação das condições naturais e os fundamentos a sociedade capitalista em seu atual estágio de desenvolvimento histórico (CARNEIRO, 2005). Estabelece-se ainda uma relação entre História Ambiental e Educação Ambiental numa perspectiva crítica, uma vez que a primeira compreende que o meio ambiente é resultado das relações sociais instituídas historicamente, e a segunda, entende o meio ambiente como indissociável da sociedade. Para uma melhor compreensão de como atuam os processos de expansão e desenvolvimento do uso do solo na Baixada Fluminense bem como a delimitação dos territórios, é necessário a reconstrução do que foi essa região em tempos remotos.

Palavras-chave: zonas de sacrifício, sociedade e natureza e industrialização.

\section{Introdução}


Este trabalho tem a pretensão de analisar a evolução industrial que a Baixada Fluminense (periferia da cidade do Rio de Janeiro) vem passando ao longo do tempo, procurando compreender como a "Baixada" surge e se configura através da apreensão de estudiosos como geógrafos, historiadores e cientistas sociais, levando-se em consideração a historicidade ambiental da região, além de compreender os reais motivos de escolha desta região para a expansão industrial.

Dos trabalhos publicados sobre a Baixada Fluminense, vários abordam a região enquanto área de bolsão de pobreza, de carência ou precariedade de uma série de serviços urbanos básicos e de infraestrutura. Alguns analisam o processo de produção do espaço materializado através dos loteamentos e da autoconstrução, outros abordam os conflitos de posseiros rurais na região, e outros contemporâneos, analisam o desenvolvimento econômico da região através da industrialização.

Acreditamos, portanto, que a história ambiental das áreas industriais é extremamente rica por trazer necessariamente em seu bojo a articulação de saberes geográfico, histórico e ecológico. Buscamos o entendimento complexo desta região tão impactada ao longo do tempo pelas transformações antrópicas e econômicos, através do referencial teórico-conceitual da ecologia política, caracterizado como um quadro reflexivo e analítico - além de político - que promove a politização e a crítica dos problemas ambientais, de sua gênese, consequências, contradições e possíveis alternativas.

Nesse sentido, segundo Lima (2009, p. 147):

\begin{abstract}
A ecologia política trouxe a contribuição das ciências humanas e sociais para a reflexão e o debate ecológico que, até então, eram pautados por leituras biologicistas e despolitizadas dos problemas ambientais. Procura, justamente, incorporar aqueles elementos que os olhares disciplinares deixavam fora da análise como: os modelos de desenvolvimento econômico-social, os interesses e conflitos de classe, os padrões culturais e ideológicos e as injuções políticas dominantes na sociedade.
\end{abstract}

Segundo Fadel (2011), o estudo da dinâmica ambiental do Estado o Rio de Janeiro revela um desastroso precedente, pois a maneira brasileira de 
ocupar novos territórios inviabilizou a existência de muitas espécies com a degradação de vários ecossistemas. De acordo com Drummond (1997, apud Fadel, 2011), "o desmatamento é um assunto doméstico para cariocas e fluminenses" e que nunca se viu tanta intensidade destrutiva em toda a história brasileira: "nenhuma outra unidade da federação sofreu tanto ou continua a sofrer mais as consequências do desmatamento de florestas do que o Rio de Janeiro" (idem, p.139).

A despeito do entendimento mais amplo sobre a relação entre história, sociedade e natureza na vida dos homens, percebe-se o quanto tem se mostrado enriquecedor os estudos que se buscam uma compreensão local de como se desenvolveu o fenômeno amplo da industrialização na organização, ocupação e uso do território.

Neste sentido, a relevância deste estudo apresenta-se à medida que busca a através da história ambiental identificar e compreender as particularidades e as recorrências de fatores que possibilitaram a expansão significativa das atuais indústrias localizadas no território da baixada fluminense; bem como descortinar um novo horizonte de explicitação dos modos de uso e de apropriação dos recursos naturais e do território, que se dá numa lógica de expansão dos empreendimentos capitalistas na região da Baixada Fluminense/RJ.

\section{A História Ambiental}

Segundo a literatura corrente, podemos considerar que a História Ambiental constitui um campo de conhecimento interessado em tratar do papel e do lugar da natureza na sociedade, ou seja, uma tentativa de (re)conceituar a história "de baixo para cima" e de colocar a natureza na história (WOSTER, 1991). Podendo, então, ser trabalhada de forma que desperte o sentimento de proteção ao ambiente natural, os valores socioambientais da comunidade, desenvolvendo a identidade com o lugar de onde se está "falando".

Para Oliveira, Duarte e Freitas (2010), para a compreensão dos processos que promovem a transformação da paisagem, a História Ambiental 
apóia-se em dois pilares constitutivos da paisagem: a cultura e o território. Neste contexto, a primeira reporta-se às formas de apreensão de recursos naturais por parte da sociedade ao longo do tempo, podendo ser compreendida como a transmissão da informação e do conhecimento em conjunção a padrões de relações materiais com o ambiente (CRUMLEY, 1994, apud Oliveira, Duarte e Freitas, 2010).

Já o território,

(...) comporta múltiplas dimensões, como a simbólica e a jurídica e se refere ao espaço geográfico sobre o qual um grupo encontra e estabelece suas condições de abrigo e sobrevivência. Assim, o território pode ser compreendido como o espaço concreto em si (com seus atributos naturais), que é apropriado (ou ocupado) por um grupo social, que por sua vez alicerça raízes e uma identidade com este espaço. (Oliveira, Duarte e Freitas, 2010, p. 127)

As diversas utilizações dos recursos (bióticos ou abióticos) através dos tempos, possibilitam o estudo da História Ambiental através da reconstituição da cultura e dos territórios ocupados pelas populações. A História Ambiental inclui a natureza como objeto de estudo, contudo ela é resultante dos processos antropológicos evolutivos no decorrer da história.

Dessa forma, de acordo com Freitas (2002, p.158 ):

É nessa nova forma de se fazer história (baseada na vida e pensamentos das pessoas comuns) que a História Ambiental se insere. E ela vai além, pois considera a terra (o meio ambiente) como um agente e uma presença na história. Isto impõe ainda uma análise mais global, na medida em que os fenômenos que ocorrem no meio ambiente não ficam restritos a fronteiras dos Estados Nacionais. E, se quisermos entende-los e associá-los à evolução das práticas sociais, precisamos ter uma visão mais integrada do mundo, que não fique restrita às fronteiras políticas.

Muitas são as contribuições da História Ambiental, tendo em vista que a é um campo eminentemente interdisciplinar, é visível o diálogo e a relação que mantém com outras áreas do saber.

\section{Relações entre a História Ambiental e a Educação Ambiental Crítica}

Na conjuntura de análise do "meio ambiente", partimos do pressuposto de que este conceito é atravessado por sentidos e interesses distintos. Trata-se de um espaço comum de recursos, contudo exposto à distintos projetos, interesses, forma de apropriação e uso material e simbólico.. 
Nesta perspectiva, afirmamos que o meio ambiente é dinâmico, que ele incorpora a ordem e a desordem ao mesmo tempo; e que os sujeitos sociais elaboram projetos distintos de uso e significação do espaço, Martinez-Alier (1996) denomina de "ambientalismo dos pobres" os segmentos sociais mais vulneráveis que têm a sua base material ameaçada e lutam por sua conservação. O ambientalismo dos pobres, ou a luta pela justiça ambiental, é marcado no Brasil, pela resistência à supremacia das intervenções no espaço pelos empreendimentos capitalistas hegemônicos.

Segundo Acserald (2001), pode-se entender que os custos ambientais foram sempre socializados e historicamente serviram como benefício do Estado para a expansão territorial capitalista no Brasil.

A socialização, localização e distribuição espacial dos custos ambientais são estrategicamente definidos pela economia mundial. Esses espaços são definidos como 'zonas de sacrifício' (Acselrad 2005), que pode ser mais bem compreendida na citação abaixo:

O capital [...] mostra-se cada vez mais móvel, acionando sua
capacidade de escolher seus ambientes preferenciais e de forçar os
sujeitos menos móveis a aceitar a degradação de seus ambientes ou
submeterem-se a um deslocamento forçado para liberar ambientes
favoráveis para os empreendimentos [...] o capital dispõe da
capacidade de se deslocar, enfraquecendo os atores sociais menos
móveis e desfazendo, pela chantagem da localização, normas
governamentais urbanas ou ambientais, bem como as conquistas
sociais [...] assim o capital especializa gradualmente os espaços,
produzindo uma divisão espacial da degradação ambiental e gerando
uma crescente coincidência entre a localização de áreas degradadas e
de residências e classes socioambientais dotadas de menor
capacidade de se deslocalizar. (ACSELRAD, 2004, p.32-33)

Dessa forma, abraçamos a Educação Ambiental na perspectiva crítica, com a finalidade de se compreender o modo como estes interesses diversos estão se fazendo presentes no campo, e sobretudo, os conflitos concebidos como disputas que, inerentes às estruturas das sociedades de dominação, opõem diferentes grupos sociais que, em condições assimétricas de poder, lutam pela atribuição de distintos significados e usos às condições naturais territorializadas. 
Esta concepção ou tendência de educação ambiental compreende a perspectiva histórico-crítico-cultural que se contrapõe aos discursos e práticas hegemônicas instituídas na realidade social.

Guimarães (2006) acrescenta sobre o caráter crítico da Educação Ambiental ao afirmar ser:

\begin{abstract}
Uma proposta voltada para o processo educativo desvelador e desconstrutor dos paradigmas da sociedade moderna com suas "armadilhas" e engajado no processo de transformações da realidade socioambiental, construtor de novos paradigmas constituintes de e constituídos por uma nova sociedade ambientalmente sustentável e seus sujeitos. (p.26)
\end{abstract}

Na mesma direção, Loureiro (2006) afirma que a Educação Ambiental Crítica, com a visão emancipatória busca por transformação social, o que engloba indivíduos, grupos e classes sociais, culturas e estruturas, como base para a construção democrática de "sociedades sustentáveis" e novos modos de se viver com a natureza.

Como forma de mudança de um olhar paradigmático da modernidade que a tudo separa em partes, fragmenta e estabelece relações de dominação e exploração, propomos a reflexão sobre relações percebidas ao mesmo tempo, como: que somos parte do meio ambiente e ao mesmo tempo somos meio ambiente como um todo; que vivemos integralmente, que somos indivíduos em sociedade e não meramente a soma de indivíduos isolados, "absolutamente autônomos", que resulta em uma determinada e reduzida compreensão de sociedade.

O que propomos com essa Educação Ambiental é uma mudança na forma de ser e estar nesse mundo que historicamente se constituiu. É pensarmos e agirmos de uma forma mais integrada e relacional, que junta 0 que foi por séculos separados; como por exemplo: a separação, que leva a dominação e exploração, entre sociedade humana e natureza. Separação vivida por todos nós, seres dessa sociedade, e que vem levando a degradação de ambos. É termos a capacidade de percebermos e agirmos de modo mais próximo a essa complexidade da realidade socioambiental, o que nos permitirá construir novas relações mais integradoras e sustentáveis socioambientalmente, nos possibilitando superar uma histórica dificuldade de 
pensarmos o junto, o conjunto e totalidades de uma forma mais integrada, sistêmica e complexa. Tudo isso para além da compreensão imperante de totalidade como apenas o resultado da soma das partes, reduzindo o que é complexo, em uma "reforma do pensamento" (Morin, 2006), construindo uma "epistemologia ambiental" (Leff, 2001).

\begin{abstract}
O desenvolvimento de uma consciência crítica que permita ao homem transformar a realidade se faz cada vez mais urgente. Na medida em que os homens, dentro de sua sociedade, vão respondendo aos desafios do mundo, vão temporalizando os espaços geográficos e vão fazendo história pela sua própria atividade criadora. (FREIRE, 2005, p. 33)
\end{abstract}

Assim, estabelece-se a relação entre História Ambiental e Educação Ambiental numa perspectiva crítica, uma vez que a primeira compreende que 0 meio ambiente é resultado das relações sociais instituídas historicamente. Então, esta analisa a história social e a história natural para que se chegue ao seu objeto. Já a segunda, entende como meio ambiente como indissociável da sociedade. Por isso é abordado nessa perspectiva, o conceito socioambiental, pois não existe sociedade sem meio ambiente, e nós homens, somos meio ambiente, e não parte do meio ambiente. Dessa maneira, as relações entre Educação Ambiental crítica e História Ambiental, se constitui num espaço social, objeto de estudo da geografia, e sobretudo, deste estudo em questão.

\title{
A Formação Territorial da Baixada Fluminense
}

Para uma melhor compreensão de como atuam os processos de expansão e desenvolvimento do uso do solo na Baixada Fluminense bem como a delimitação dos territórios especialmente protegidas (Áreas de Proteção Ambiental, Parques Naturais, entre outros) é necessário a reconstrução do que foi a Baixada Fluminense em tempos remotos.

Segundo Tavares (2010), a Baixada Fluminense é uma região onde não há consenso sobre quais municípios compõem seu território, pois, seus municípios estão considerados são parte componente de parte da região metropolitana do Rio de Janeiro (núcleo metropolitano) de acordo com a classificação do IBGE (Instituto Brasileiro de Geografia e Estatística), ora estão 
definidos como um enfoque político-institucional para fins de planejamento, a SEDEBREM (Secretaria de Estado de Desenvolvimento da Baixada e Região Metropolitana). Há ainda uma regionalização histórico-cultural, de acordo com o CIDE-RJ (Centro de Informações e dados do Estado do Rio de Janeiro), que baseia-se na formação social da área.

Municípios Fluminenses segundo as regionalizações:

\begin{tabular}{|c|c|c|}
\hline $\begin{array}{l}\text { Região Metropolitana } \\
\text { (IBGE) }\end{array}$ & SEDEBREM & CIDE-RJ \\
\hline $\begin{array}{l}\text { Belford Roxo, Duque de } \\
\text { Caxias, Guapimirim, } \\
\text { Itaboraí, Japeri, Magé, } \\
\text { Maricá, Mesquita, } \\
\text { Nilópolis, Niterói, Nova } \\
\text { Iguaçu, Queimados, Rio } \\
\text { de Janeiro, São } \\
\text { Gonçalo, São João de } \\
\text { Meriti, Tanguá }\end{array}$ & $\begin{array}{l}\text { Belford Roxo, Duque de } \\
\text { Caxias, Guapimirim, } \\
\text { Itaguaí, Japeri, Magé, } \\
\text { Mesquita, Nilópolis, } \\
\text { Nova Iguaçu, } \\
\text { Paracambi, Queimados, } \\
\text { São João de Meriti, } \\
\text { Seropédica }\end{array}$ & $\begin{array}{l}\text { Belford Roxo, Duque de } \\
\text { Caxias, Japeri, } \\
\text { Mesquita, } \\
\text { Novarópolis, } \\
\text { Queimados, São João } \\
\text { de Meriti. }\end{array}$ \\
\hline
\end{tabular}

A ocupação inicial das terras dessa região relaciona-se com a fundação da cidade do Rio de Janeiro, em 1585. Assim, como a distribuição de sesmarias na Baia de Guanabara aos nobres e militares portugueses (SIMÕES, 2007). Fisicamente, a Baixada Fluminense tem como principais características uma planície flúvio-marinha rasa, desenvolvendo-se entre o sopé da Serra do Mar e o Oceano Atlântico, interrompida por colinas e maciços costeiros.

Assim, a história ambiental da Baixada Fluminense configurou-se meio à expansão desordenada da população, que ocupou a região no primeiro momento para a agricultura e, posteriormente, veio a indústria. Nesse ínterim, não houve preocupação com as formações naturais nativas, caso semelhante a outras regiões do país. 


\section{Breve Contexto Histórico da Baixada Fluminense}

Em 1990 no final do governo de Moreira Franco, a Baixada Fluminense foi considerada como "parte de um conjunto maior conhecido como Baixada da Guanabara correspondendo a uma faixa de terras baixas de largura variável, no entorno da baía do mesmo nome" no Plano de Ação Integrada da Baixada Fluminense (PAl). Pretendendo contornar a situação caótica em que se encontrou a região após as chuvas de 1988, este visava a realização de várias obras de infraestrutura, recuperação urbana e atingia os setores de educação e saúde. Os municípios aí inseridos são os de Duque de Caxias, Nova Iguaçu, Nilópolis e São João de Meriti e estes foram alvo das propostas de obras empreendidas neste governo.

Dando segmento as obras do Programa Reconstrução Rio, o governo sucessor de Moreira Franco, Leonel Brizola imprimiu ao projeto um caráter não apenas emergencial, mas de perspectiva global em saneamento na Baixada Fluminense. Em função das políticas setoriais o Projeto não foi bem desenvolvido. Com a gestão do governo sucessor de Leonel Brizola, Marcelo Alencar, o Reconstrução Rio teve suas principais obras realizadas.

$\mathrm{Na}$ gestão do governador Anthony Garotinho, através da entidade executora, Secplan realizou-se uma revisão das obras da primeira fase do projeto para começar as da segunda fase, e o Projeto passou a ser chamado Nova Baixada. Com o objetivo de orientar as ações do Governo do Estado na Baixada Fluminense foi criada em 1999, a Secretaria de Desenvolvimento da Baixada (SEDEB) pelo governador Anthony Garotinho. A SEDEB ficou vinculada à SECPLAN e tem como uma das suas funções básicas encaminhar as principais reivindicações dos moradores da Baixada ao Governo. São incluídos na Baixada Fluminense, segundo a SEDEB, os municípios de Duque de Caxias, São João de Meriti, Belford Roxo, Queimados, Guapimirim, Seropédica, Itaguaí, Nova Iguaçu, Magé, Nilópolis, Japeri e Paracambi.

A criação e o posterior crescimento dos movimentos sociais na Baixada foram acompanhados pelo surgimento de diversas instituições culturais, especialmente as casas e centros de cultura, que se espalharam pela Baixada 
para promoverem cursos, "resgatarem a cultura local" e participarem ativamente na construção da "cidadania" para os moradores.

Apesar do estigma de violenta, a Baixada Fluminense tem recebido investimentos de grandes indústrias. Em 1999 foi inaugurado o parque gráfico de um dos maiores jornais do país em Duque de Caxias, o projeto de um Parque Tecnológico para Xerém (distrito de Duque de Caxias) prevê a geração de mil empregos diretos e cinco mil indiretos. Queimados que já possuí em seu território dezesseis indústrias de grande porte, incluindo uma das maiores fábricas de refrigerantes e cerveja, receberá mais nove grandes empresas.

A atração das empresas pela Baixada deve-se à proximidade desta região à cidade do Rio de Janeiro, e a existência de vias de fácil acesso que cortam a área, como as Rodovias Presidente Dutra e Washington Luís e a via expressa Linha Vermelha. No caso de Queimados acrescenta-se a instalação do Distrito Industrial e também a proximidade ao Porto de Itaguaí. Em desenvolvimento estão as obras do Arco Rodoviário (Arco Metropolitano) do estado do Rio de Janeiro, que visa concretizar uma ligação eficiente e rápida entre o polo portuário e siderúrgico de Itaguaí, a oeste, e o polo petroquímico de Itaboraí, a leste. Atualmente Itaguaí conta com investimentos advindos de empresas como a Companhia Siderúrgica do Atlântico, localizada em Santa Cruz, bairro do Rio de Janeiro vizinho a cidade, além do Porto de Itaguaí, novos portos privados, como o Super Porto Sudeste do grupo MMX-LLX, de estaleiros civil e militar que estão se instalando na cidade. Todo esse processo vem dinamizando intensamente a economia local da Baixada Fluminense, onde a promessa de crescimento para a área é grande, bem como a geração de empregos. Crescimento este que vem atrelando à novas formas de exploração na região.

Exploração esta que pode ser destacada a partir das obras previstas na IIRSA (Iniciativa para a Integração da Infraestrutura Regional Sul-Americana) e no PAC (Programa de Aceleração do Crescimento) que têm grandes contribuições de recursos de IFMs (Instituições Financeiras Multilaterais) e do BNDES (Banco Nacional de Desenvolvimento Econômico e Social), e são localizadas em regiões estratégicas para o país objetivando viabilizar a 
integração dos mercados nacional e sul-americano. Com o objetivo de atrair investimentos, o Estado, em suas diversas esferas (municipal, estadual e federal), vem concedendo incentivos fiscais e subsídios para as empresas se instalarem na região, ao mesmo tempo, se omitindo no seu papel de fiscalizador e na exigência do cumprimento das legislações vigentes.

A política altamente permissiva do governo em termos ambientais e no que tange aos grandes empreendimentos industriais tem ocupado um papel chave na atração de empreendimentos industriais altamente impactantes para a Baixada Fluminense, cujo destino final dos produtos é predominantemente 0 mercado externo. Ou seja, a produção é voltada para as necessidades do mercado global, onde a lógica é internalizar os ganhos/lucros, e externalizar os impactos adversos e os custos da produção, principalmente as populações mais vulneráveis, conforme descrito em tópico anterior.

\section{A Industrialização e a Natureza}

Lefebvre (2001) em O direito à cidade - Industrialização e Urbanização, acrescenta a análise que a sociedade urbana define a nossa realidade social. O processo de industrialização é o motor de transformação da sociedade, é o indutor, e os induzidos são problemas relativos ao crescimento e planificação, questões referentes à cidade e ao desenvolvimento da realidade urbana, do lazer e da cultura.

A cidade é anterior à industrialização e, as criações urbanas mais belas (obra = aquilo que tem valor de uso; produto = aquilo que tem valor de troca) datam de antes da indústria. No processo histórico, a burguesia substitui a aristocracia, e junto com a democracia substitui também a opressão pela exploração, e com isso, substitui a obra pelo produto. E nesse jogo de substituições, a natureza vira um produto valioso, uma vez que gera recursos necessários para a produção industrial.

Nessa lógica, Carneiro (2005, p. 33) enfatiza:

Do ponto de vista da lógica da concorrência pela maior rentabilidade no jogo da acumulação privada de riqueza abstrata, as "propriedades sensíveis" das coisas naturais só interessam na medida em que podem ser convertidas em coisas monetárias. Nessa perspectiva, por exemplo, uma montanha não é uma referência geográfica ou uma 
paisagem a que se está efetivamente vinculado, nem um elemento fundamental na manutenção do clima local, nem ainda um terreno onde se pode plantar aquilo de que necessita para comer, ou onde se pode construir a casa em que se pode morar, e sim um conjunto naturalmente produzido de meios, isto é, de matérias-primas (minérios, madeiras) e condições (o solo, a forma do relevo, uma vista panorâmica que permita auferir sobrelucro na construção e venda de residências...) que podem se utilizadas para a acumulação da única quantidade que conta, ou seja, a moeda.

Dessa forma, a natureza fica sob o domínio socioeconômico, uma vez que a partir dela resultam as ferramentas de trabalho, os modos de produção e as relações sociais. Só que este domínio socioeconômico do sistema do capital tem como característica o crescimento da produção a todo custo e 0 aniquilamento dos recursos naturais, gerando sérios problemas ambientais em escala globalizada, mais conhecido como a crise ambiental. Só que esta crise tem como cerne o estilo de desenvolvimento vigente considerado insustentável que explora a natureza e a vida humana dos mais injustiçados socialmente.

No entanto, acreditamos que para lidarmos com essas questões da atualidade, devemos ter como premissas primeiro que o meio ambiente preservado é essencial a qualidade de vida. Segundo, que é um bem coletivo (de todos) de uso comum e que, portanto, teremos que enfrentar uma contradição fundamental em nossa sociedade: a de se priorizar a apropriação privada (particular) do meio ambiente nas relações predominantes do modo de produção capitalista em seu processo de desenvolvimento. Isso nos leva a considerar também como pressuposto, que para o enfrentamento dessa crise socioambiental globalizada, a preservação do meio ambiente é um direito e dever de todos na sociedade.

Com isso, fazer emergir a construção das condições sustentáveis de continuidade da vida, que é de todos e para todos, e não apenas do interesse de uma parte da sociedade que teve o privilégio de usufruir das melhores condições de vida que a atual forma de organização social (em crise) veio produzindo até aqui.

"Estamos diante de um momento crítico na história da Terra, numa época em que a humanidade deve escolher o seu futuro. À medida que o mundo torna-se cada vez mais interdependente e frágil, o futuro reserva, 
ao mesmo tempo, grande perigo e grande esperança. Para seguir adiante, devemos reconhecer que, no meio de uma magnífica diversidade de culturas e formas de vida, somos uma família humana e uma comunidade terrestre com um destino comum. Devemos nos juntar para gerar uma sociedade sustentável global fundada no respeito pela natureza, nos direitos humanos universais, na justiça econômica e numa cultura da paz. Para chegar a este propósito, é imperativo que nós, os povos da Terra, declaremos nossa responsabilidade uns para com os outros, com a grande comunidade de vida e com as futuras gerações."

(Preâmbulo - Carta da Terra)

\section{Considerações Finais}

Os traços significativos da História Ambiental nos remete aos sentimentos de identidade, de compromisso e de cidadania, o que só é possível quando conhecemos nossas origens, nosso território e os usos que dele fazemos (Oliveira, Duarte e Freitas, 2010). Assim, faz-se necessário compreendermos como as nossas ações do passado influenciam e acabam por determinar o presente.

A Baixada Fluminense, região rejeitada por alguns e de grande valor para outros, representa lócus de pesquisa nas diferentes dimensões, política, econômica, socioambiental, etc. Observamos que há, ainda, uma carência de literatura a respeito desta região, que ainda é símbolo de descaso, principalmente pelo poder público. Por este motivo, consideramos significativo designá-la como 'zona de sacrifício' (Acselrad, 2005).

A História Ambiental dessa região é marcada por intensa exploração, natural e social. Recuperar como os seres humanos afetaram e foram afetados na convivência do seu meio contribui para que possamos (re)pensar o que deixamos de herança para as futuras gerações. Desta forma, consideramos que a História Ambiental representa um recurso de análise viável para caracterização e (re)conhecimento do território, contribuindo assim para reflexões acerca do "chão" onde fincamos nossas raízes.

\section{Referências Bibliográficas}


ACSELRAD, H. As práticas espaciais e o campo dos conflitos ambientais. In: Conflitos ambientais no Brasil. Rio de Janeiro: Relume Dumará: Fundação Heinrich Boll, 2004, p. 13-35.

. Apresentação. In: A insustentável leveza da política ambiental desenvolvimento e conflitos socioambientais. Belo Horizonte: Autêntica, 2005.

CARNEIRO, E.J. Política Ambiental e a ideologia do desenvolvimento sustentável. In: A insustentável leveza da política ambiental desenvolvimento e conflitos socioambientais. Belo Horizonte: Autêntica, 2005, p. 27-47.

CARTA DA TERRA. (texto coletivo). Disponível em: http://www.cartadaterrabrasil.org/prt/text.html, acessado em 21 de fev. de 2011. FADEL, S. História da devastação e preservação dos elementos naturais de mata atlântica da Baixada Fluminense. Anais do XXVI Simpósio Nacional de História. São Paulo, 2011

FREIRE, P. Pedagogia do Oprimido. Rio de Janeiro: Paz e Terra, 2005.

FREITAS, de A. I. A geografia na construção de uma história ambiental brasileira. Boletim Goiano de Geografia. 22(2): 155-168. jul/dez.2002.

GUIMARÃES, M. (org.) Caminhos da Educação Ambiental: da forma a ação. Campinas, Papirus, 2006.

KURZ, R. O colapso da modernização: da derrocada do socialismo de caserna à crise da economia mundial. Rio de Janeiro: Paz e Terra, 1996.

LEFEBVRE, H. O direito à cidade: Industrialização e Urbanização. Centauro, 2001

LEFF. E. Epistemologia Ambiental. São Paulo, Cortez, 2001. 
LIMA, G.F. da C. Educação ambiental crítica: do socioambientalismo às sociedades sustentáveis. Educação e Pesquisa, São Paulo, v. 35, n.1, p.145163, jan-abr/2009.

LIPIETZ, A. A ecologia política: solução para a crise da instantânea política? In: ALIMONDA, H. (Ed.) Ecologia Política. Buenos Aires: CLACSO, 2002.

LOUREIRO, C. F. B.; LAYRARGUES, Philippe Popmier; CASTRO Ronaldo Souza de (Orgs.) Pensamento complexo, dialética e educação ambiental. São Paulo, Cortez, 2006.

MARTINEZ-ALIER, J. Justiça ambiental (local e global). In: CAVALCANTI,C. (Org.). Meio ambiente, desenvolvimento sustentável e políticas públicas. São Paulo: Cortez, Recife: Fundação Joaquim Nabuco, 1999, p.215-231.

MORIN, E. Os sete saberes necessários à educação do futuro. $11^{\text {a }}$ ed - São Paulo. Cortez, 2006.

OLIVEIRA, R.R., DUARTE, P.A. \& FREITAS, I.A. Trabalhando a História Ambiental em uma floresta urbana: o Parque Municipal de Nova Iguaçu. In: Educação ambiental: formação de valores ético-ambientais para o exercício da cidadania no município de Nova Iguaçu. Rio de Janeiro: PUC-Rio, 2010

SIMÕES, M.R. A Cidade Estilhaçada: reestruturação econômica e emancipações municipais na Baixada Fluminense. Rio de Janeiro: Entorno, 2007.

TAVARES, F.R. 0 cinza que se expande pelo verde que se vende: geração de estratégias através de condições de conflitos na baixada Fluminense. Anais do XVI Encontro nacional de Geógrafos. Porto Alegre, 2010.

WROSTER, D. Para fazer história ambiental. Estudos Históricos, Rio de Janeiro, vol. 4, n. 8, p. 198-215, 1991. 